\title{
"Chega lá e Eudora!": ativismo e discurso inspiracional na campanha publicitária de uma marca-coaching
}

\author{
Emanuelle Gonçalves Brandão Rodrigues \\ Universidade Federal de Pernambuco \\ Danyelle Alves da Paixão \\ Thainá Evellyn Martiniano Alexandre \\ Universidade Federal de Alagoas
}

\begin{abstract}
Resumo
Busca-se investigar, a partir do estudo de caso da campanha publicitária "Chega Lá e Eudora!", como o discurso inspiracional típico do mercado de autoajuda tem promovido mudanças na publicidade contemporânea, em especial no mercado de cosméticos, conhecido por reforçar estereótipos e padrões de beleza. Para tanto, partimos da noção de ethos (Maingueneau, 2008; Eggs, 2013) para analisar como a marca Eudora constrói sua imagem baseada em formas de ativismo social. Nos debruçamos em um corpus ampliado de peças publicitárias em diversos formatos, tendo como corpus restrito os vídeos divulgados pela marca em seu canal no YouTube, cujo público-alvo são consumidoras e mulheres que buscam aumentar sua renda com a venda de cosméticos. O estudo demonstra como as narrativas de autoajuda se apresentam como formato ideal para a promoção de uma imagem de si das marcas, a exemplo da Eudora, em conformidade com as diferentes formas engajamento e ativismo social.
\end{abstract}

\section{Palavras-chave:}

Publicidade. Cultura da inspiração. Ativismo social. Ethos ativista. Discurso de autoajuda.

\section{Introdução}

Eu nasci sem a mão e o antebraço esquerdo, uma deficiência congênita. Na adolescência você vai se descobrindo quem você é e aí eu comecei a lançar, assim, uns visuais mais marcantes, comecei a mudar o foco da atenção para a minha personalidade, para o meu cabelo, para o meu visual, para minha maquiagem. Isso me fortaleceu muito [sic]'

1 Trecho do vídeo Mulheres que inspiram a chegar lá: Gabe Maruyama | Eudora. Disponível em: <https://www.youtube.com/watch?v=J1nhTHdL8AU> Acesso em 08 de nov. de 2018

Revista Ícone (ISSN 2175-215X) • DOI: 10.34176/icone.v17i2.239051

Recife, Vol. 17, N. 2, 142-157, ( 2019 PPGCOM/UFPE.

Artigo recebido em 30 nov. 2018 e aprovado em 5 mai. 2019.

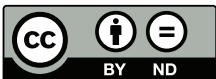


Com 370.113 visualizações, o vídeo publicado no canal da Eudora, no Youtube, faz parte de uma campanha da marca que tem como proposta motivar, ensinar e inspirar mulheres a "voltar o foco para o que realmente importa: sua personalidade"2. Ancora-se, para tanto, em uma narrativa de autoajuda que estimula mulheres a produzirem o melhor de si mesmas a partir de um discurso inspiracional que reúne coragem, força e delicadeza como características próprias de mulheres empoderadas.

As práticas de autoajuda enquanto técnicas de produção de si não são tão recentes, mas assumem uma dimensão singular na cultura contemporânea, na qual as mídias se apresentam como agenciadoras de uma pedagogia comum. De fato, elas se ancoram em uma tradição milenar de práticas dirigidas ao governo de si, como a meditação e a escrita sobre si (MARÍN-DIAZ, 2011). Mas ao se inscreverem em espaços e tempos distintos, essas práticas também refletem o espírito do tempo, estimulando a produção de afetos ligados aos modos de conduta em questão.

A inspiração enquanto cultura (CASAQUI, 2017) parece estimular um trabalho ético que busca "transformar a si mesmo em sujeito moral de sua própria conduta", "propondo-se como exemplo ou buscando dar à vida pessoal uma forma que corresponda a critérios de esplendor, beleza, nobreza ou perfeição" (FOUCAULT, 1985, p.27). Essa ética encontra sua ancoragem no que Casaqui $(2017$, p.6) chama de ideologia do empreendedorismo, altamente "disseminada a partir de produtos "inspiracionais" dos mais diversos", a exemplo da publicidade contemporânea, que tem incorporado de forma "competente" o ethos ativista em seus discursos.

A tentativa de persuadir os consumidores quanto aos valores atribuídos à marca pode ser explicada a partir da noção de ethos, cuja prova, segundo Maingueneau (2008, p.56), consiste em "causar boa impressão mediante a forma com que se constrói o discurso", em produzir uma imagem da marca capaz de convencer a audiência. Além disso, conforme explica o autor, a noção permite refletir sobre o processo de adesão dos sujeitos à determinadas posições discursivas, o que implica também conhecimento sobre as cenas em que se constroem e circulam esses discursos.

Em se tratando de Publicidade, a produção dessas narrativas existenciais parece alcançar seu ápice comercial, especialmente no mercado de cosméticos, cujos discursos pedagógicos e de autoajuda antecedem a Eudora: eles estão lá na Dove, Natura, Avon e Boticário, para citar só alguns exemplos. Tendo como noção central a aprendizagem, o discurso materializado nas campanhas dessas marcas utiliza como recurso estratégico o que Marín-Diaz (2011, p.10-11) define como a

condução das condutas de indivíduos que se consideram a si mesmos como agentes autônomos e empresários de si mesmos, indivíduos dispostos a se transformar e incrementar seu capital (freelancer) para alcançar a ascensão social e profissional.

2 Disponível em: <https://www.youtube.com/watch?v=J1nhTHdL8AU > Acesso em 08 de nov. de 2018 
Dessa forma, inspirar, motivar e superar são verbos comumente evocados no discurso das marcas que se apropriam de temas sociais para produzirem campanhas engajadas socialmente. Ao incorporar o ethos ativista, elas visam atribuir aos seus produtos e serviços valores associados ao bem-estar social, reivindicados por diferentes formas de ativismos, cujo "objeto de desejo é a transformação social" (DOMINGUES, 2018, p.78). A vinculação desse ethos ao discurso de autoajuda se mostra como a expressão do capitalismo afetivo, na qual "discursos e práticas afetivos e econômicos moldam uns aos outros", produzindo o que Illouz (2011, p.12) percebe "como um movimento largo e abrangente em que o afeto se torna um aspecto essencial do comportamento econômico".

O mito da superação pessoal emerge nesses discursos para suplantar, de acordo com Casaqui (2017), o cenário de desigualdade social, onde ser empreendedor de si mesmo aparece "como forma de ultrapassar qualquer obstáculo e injustiça social, como fórmula mágica para se alcançar o sucesso" (CASAQUI, 2017, p.2). Mas para que gere efetivamente adesão dos enunciatários, o sujeito do discurso precisa afiançar as posições que assume, apresentando exemplos que associem sucesso e superação à imagem que constrói de si.

A Eudora, marca que pertence ao grupo "O Boticário", foi fundada em 2011 e se evidencia por meio de suas campanhas publicitárias com a participação de mulheres em destaque no cenário midiático brasileiro, como as atrizes globais Grazi Massafera, Marina Rui Barbosa, Juliana Paes e a cantora Claudia Leitte. Além desses nomes, a marca traz relatos de mulheres comuns com uma vida profissional bem estabelecida, como a jogadora de futebol profissional Aline Calandrini, a consultora focada em diversidade étnico-racial Patrícia Santos e a diretora de filmes, fotógrafa e montadora Gabe Maruyama.

O que todas elas têm em comum? Uma história de superação e conquistas, construída segundo uma narrativa comum demarcada por uma estética própria da mitologia da autorrealização (EHRENBERG, 2010, p.13), na qual "o sucesso empreendedor é considerado como a via real do sucesso.

Nesse sentido, a proposta deste artigo consiste em investigar, a partir do estudo de caso campanha publicitária “Chega Lá e Eudora!", como o discurso inspiracional típico do mercado de autoajuda tem promovido mudanças na publicidade contemporânea, em especial no mercado de cosméticos, conhecido pelo reforço de estereótipos e padrões de beleza. Para tanto, partimos da noção de ethos (MAINGUENEAU, 2008; EGGS, 2013) para analisar como a marca Eudora constrói sua imagem baseada em formas de ativismo social. Nos debruçamos em um corpus ampliado de peças publicitárias em diversos formatos, tendo como corpus restrito os vídeos divulgados pela marca em seu canal no Youtube, cujo público-alvo são consumidoras e mulheres que buscam aumentar sua renda com a venda de cosméticos.

\section{"Chega lá e Eudora": o ethos ativista de uma marca-coaching}

Lançada em fevereiro de 2011, a Eudora é umas das unidades de negócio do 
Grupo Boticário, holding do segmento de beleza que compõe sua cartela de marcas com mais outras três: "O Boticário", "Quem disse, Berenice?" e "The Beauty Box". Com a proposta de "ajudar as mulheres a fazerem a sua vida acontecer", a marca lançou em 2018 a campanha "Chega Lá e Eudora”, dirigida a um público feminino composto principalmente por consumidoras e mulheres que buscam aumentar sua renda com a revenda de cosméticos.

Tendo como ideia norteadora "estimular as mulheres a traçarem seus caminhos e conquistarem os objetivos, fazendo a vida acontecer através do seu protagonismo"4, a campanha lança mão do conceito de marca-coaching, fazendo o papel de especialista ao lado de suas consumidoras. Assim, Eudora se inscreve em um contexto de profusão de discursos especializados, orientando sua comunicação para a promoção do aperfeiçoamento contínuo. A mudança de posicionamento acaba por enfatizar sua ancoragem nas premissas da autoajuda como ponta de partida para a estruturação do ethos da marca.

Mobilizar a afetividade do enunciatário requer do ethos a promoção de uma experiência sensível do discurso (MAINGUENEAU, 2008). E como condição essencial para adesão dos consumidores, o ethos mantém um laço privilegiado com o discurso publicitário, visto que, segundo o autor, toda propaganda deve encarnar por meio de sua enunciação aquilo que ela prescreve. Não menos importante, a adesão voluntária ao discurso implica também uma pré-disposição a certas formas de ação e engajamento.

No tocante às pautas feministas e de outras formas de ativismo social, sua emergência no mercado publicitário brasileiro tem seu marco em 2013 com a campanha "Real Beleza", da Dove. Não por acaso, é nesse mesmo ano que diversas pautas ativistas são levadas às ruas pelos movimentos sociais, ocupando um espaço importante não apenas na agenda da mídia, como também na agenda pública. É a partir desse período que começamos a ver com maior ênfase a mudança de posicionamento de marcas de diversos segmentos de mercado, especialmente de cosmético, moda e bebida. Isso ocorre, em primeiro lugar, como uma tentativa de incorporar a crítica à manutenção de padrões hegemônicos de comportamento e beleza e, em segundo, como necessidade de reforçar os laços com seu público através da representação dos consumidores "reais" em suas campanhas.

Essa mudança de valores - ou ao menos na forma como os mesmos valores são apresentados - encontra sua guarida nas marcas direcionadas sobretudo para o público feminino. Nesse contexto, Eudora parece se enunciar com um tipo ideal de marca "amiga", apresentando, ao mesmo tempo, conselhos e sugestões de como aceitar a si mesma e a diferença inerente a essa identidade. $\mathrm{O}$ compromisso com a alteridade se constrói por meio da incorporação de um ethos associado à luta por direitos igualitários, pela representatividade de minorias e pelo respeito à diferença, evocando em

3 Disponível em: <https://www.eudora.com.br/> Acesso em 08 de nov. de 2018

4 Disponível em: <https://www.mundodomarketing.com.br/noticias-corporativas/conteudo/174851/com-linguagem-digital-eudora-eleva-o-protagonismo-feminino-em-campanha-nacional > Acesso em 08 de nov. de 2018. 
seu discurso diferentes vozes. Mas o que torna a construção de sua imagem um caso particular é o modo como articula o consumo de cosméticos, tradicionalmente ligado à padronização identitária e ao apagamento da diferença, a formas de autonomia individual: "seja com produtos, serviços, conteúdos ou oportunidades, Eudora está sempre buscando maneiras para estimular que cada mulher faça a sua vida acontecer"

É nesse sentido que um tipo de ethos parece ser cada vez mais incorporado pelas marcas, a exemplo da Eudora: o ativista. Seu consumidor não é necessariamente um ativista, mas os valores ligados a certas causas sociais são apropriados de modo a produzir uma justificativa moral para aderir ao discurso das marcas. E, nesse contexto, há dois tipos de consumidores, segundo Domingues e Miranda (2018): o consumidor ativista, que busca conduzir suas práticas de consumo conforme o discurso que sustenta, e o consumidor de ativismo, aquele que não necessariamente articula seu discurso com as práticas de responsabilidade social. Este último, ao que parece, é o grande público para o qual essas marcas direcionam seu discurso.

No novo posicionamento, os produtos da Eudora são ressignificados de modo que seu consumo representa valores como autonomia, liberdade e sucesso. E tudo isso por uma grande causa: a liberdade para a mulher ser quem ela quiser, livre de preconceitos e sem rivalidades com indivíduos do mesmo sexo. A responsabilidade social aparece como valor essencial da marca, seja pela não realização de testes em animais, segundo lista do Projeto Esperança Animal (PEA), ou pela forma de lidar com a diferença. Contudo, é preciso ressaltar que não se trata de uma marca ativista, o que pode ser compreendido pelo tipo de consumo que promove: ainda que o respeito a diferença seja determinante em seu discurso, a noção de bem-estar que o atravessa é essencialmente individual.

A relação bem-sucedida entre consumo, ativismo e autoajuda é possível porque para gerar adesão, o capitalismo produz o que Boltanski e Chiapello (2009) chamam de alças de cooptação, atraindo sujeitos que ocupam posições de minorias com o objetivo de lhes oferecer formas dissimuladas de opressão. Com isso, "pode-se dizer então que o capitalismo "coopta", pela instauração de novas modalidades de controle, a autonomia consentida" (BOLTANKSI; CHIAPELLO, 2009, p.424). Esse trabalho de promoção da libertação por meio de dispositivos opressivos aparece como mola propulsora do espírito do capitalismo, materializando-se no que se apresenta como um de suas principais ferramentas de cooptação: a publicidade.

Ao se mostrar nas escolhas efetuadas pelo enunciador, o ethos, de acordo com Eggs (2013), é resultado da articulação entre phrónesis (razão), aretê (virtude) e Eúnoia (benevolência). Mas o convencimento pelo discurso implica não apenas um ethos que articule essas três dimensões, mas também o pathos (afetos), "que deve ser a expressão adequada do tema tratado, do ethos do orador e do ethos do auditório" (EGGS, 2013, p. 42).

Considerando que o valor de uso dos produtos Eudora, assim como de outras marcas de cosméticos, não carece de uma retórica criativa - seu logos (razão) convence

5 Disponível em: <https://loja.eudora.com.br/institucional/quem-somos> Acesso em 08 de nov. de 2018. 
por si mesmo -, afinal, a função principal da maquiagem é mudar o visual, o aparato justificativo do capitalismo parece se concentrar mais nas dimensões do ethos e do pathos. Então, para que o ativismo social se evidencie como valor da marca, ele precisa de algum modo tocar seu público, apontando para referências de outra ordem que não a da pura acumulação do capital (BOLTANSKI; CHIAPELO, 2009) ou do consumo supérfluo.

É nesse contexto que surge o conceito marca-coaching, que deriva hoje em dia de um conjunto de práticas profissionais voltadas para a gestão individual da carreira e da vida pessoal. Os coaches têm atuado em diversas áreas, oferecendo aconselhamos que se vinculam muito mais a uma filosofia de vida direcionada ao mercado de trabalho do que a técnicas específicas de cada campo de atuação. Nesse sentido, podemos dizer que suas narrativas são fortemente alicerçadas no discurso de autoajuda, direcionando o indivíduo para ações eficientes sobre si mesmo.

Ao sugerir que existe um caminho para "chegar lá" e que a autoestima é um fator importante para fazer a jornada da vida acontecer, a marca desenvolve uma narrativa comum aos testemunhos religiosos, cuja estrutura segue uma linha do tempo própria aos relatos biográficos: sofrimento, conversão, metanóia e conquista. Esse é o pano de fundo das diferentes formas em que a marca se enuncia, evidenciando-se principalmente nos relatos de superação das empreendedoras individuais.

Contudo, o que nos parece mais interessante é o modo como a marca articula em suas práticas pedagógicas as dimensões pública e privada, reinventando as formas do político na esfera do consumo. A autoajuda emerge em seu discurso não apenas como forma de otimizar as ações do indivíduo sobre si, mas também como experiência pública de (re)existência, portanto de diferentes formas de fazer política. Assim é que o corpo aparece, em sua campanha, como alvo das ações sobre si, para si e entre si.

"Mais que uma campanha, a plataforma criada pela Talent Marcel atende todos os nossos públicos e pontos de contato. De consumidoras a Representantes. Queremos que todas cheguem lá e sejam protagonistas das suas vidas"6. A proposta de marca-coaching se ancora na dimensão pedagógica do discurso de autoajuda para ensinar as mulheres exercitarem seu potencial empreendedor. $\mathrm{O}$ foco na aprendizagem aparece aqui como noção central que articula os discursos pedagógico e de autoajuda, concentrando, como indica Marín-Diaz (2015, p.10), "sua ação na produção de um indivíduo que age sobre si utilizando exercícios de treinamento intelectual e emocional para se transformar permanentemente".

Os teasers lançados pela Eudora se organizam em quatro grandes séries: (1) situações do cotidiano com as porta-vozes da marca; (2) Desafio Eudora; (3) Eudora responde; e (4) Mulheres que inspiram a chegar lá. Todos protagonizados por três perfis de "mulheres que inspiram": (1) e (2) celebridades; (2) Influenciadoras digitais; e (4) empreendedoras. Buscando analisar como a Eudora atualiza seu posicionamento em

6 Sleyman Khodor, Diretor de Criação da TALENT MARCEL, agência que cuida da comunicação da marca. Disponível em: <https://www.mundodomarketing.com.br/noticias-corporativas/conteudo/174851/com-linguagem-digital-eudora-eleva-o-protagonismo-feminino-em-campanha-nacional> Acesso em 08 de nov. de 2018. 


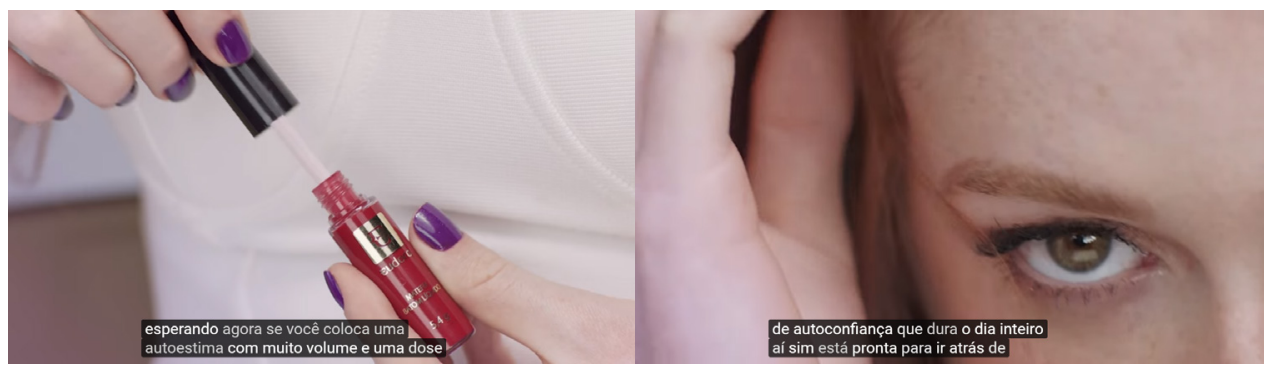

Figura 1 - Marina Ruy Barbosa e as Oportunidades. Reprodução/YouTube.

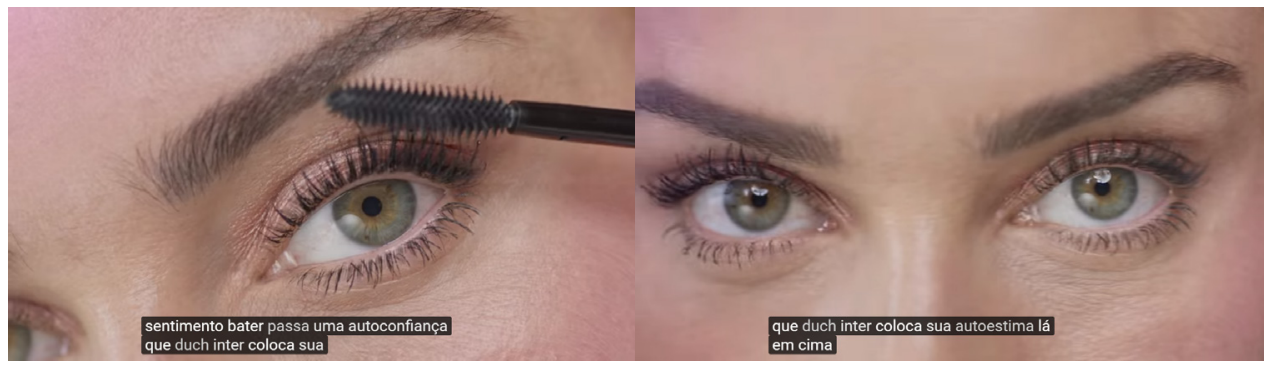

Figura 2 - Marina Ruy Barbosa e Grazi Massafera em Quem Nunca. Reprodução/YouTube.

uma perspectiva inspiracional de ancoragem pedagógica, nos debruçamos, no próximo tópico, sobre a plataforma “Chega lá e Eudora!" e seus produtos de comunicação.

\section{"Mulheres que inspiram a chegar lá": uma análise da campanha publicitária da marca Eudora}

Ressaltar a trajetória das mulheres para conquistar seus objetivos e encorajá-las a isso é a proposta da campanha "Chega lá" . Embora o título se refira a uma série específica da plataforma "Chega lá e Eudora!", a frase representa um lema maior que guia a campanha publicitária da marca Eudora. Trata-se de uma campanha/plataforma que mobiliza temas como autoconfiança, autoestima e sucesso, estabelecendo uma relação de proximidade com as consumidoras através de paralelos com situações cotidianas comuns às brasileiras batalhadoras. Demonstra, nesse cenário, como vivenciar melhor esses momentos com toques de beleza, autoestima e autoconfiança (Figuras 1 e 2).

Os frames acima são de vídeos protagonizados pelas atrizes Marina Ruy Barbosa e Grazi Massafera, ambas porta-vozes da Eudora. Eles fazem parte da série $1 \mathrm{da}$ campanha, "situações do cotidiano", e visam, segundo a marca, personificar a "mulher que inspira", pois consideram essas atrizes "mulheres fortes com trajetórias pessoais e profissionais de conquista. As duas trabalham desde muito cedo, estudam e realizam

7 Disponível em: <http://www.meioemensagem.com.br/home/marketing/2018/04/02/com-suas-consumidoras-eudora-quer-chegar-la.html> Acesso em 08 de nov. de 2018. 
diversos papéis em suas vidas"8.

Com uma trajetória em comum no showbusiness, as atrizes são apresentadas pela marca como fiadoras desse protagonismo, silenciando qualquer marca distintiva que as separem da maioria das mulheres brasileiras, público ao qual esse discurso inspiracional se dirige. Em relatos nas diferentes mídias, elas já levantaram essa questão, sempre ressaltando os percalços em suas trajetórias profissionais: "Posso dizer que trabalho desde os 9 anos, sempre amei atuar e soube o que queria para minha vida. Sou focada, e tudo aconteceu aos poucos. [...] Tudo o que tenho é porque trabalho pra caramba", desabafa Marina em entrevista para O Globo9. A atriz, que faz questão de lembrar que trabalha desde criança, explica que precisou "ter disciplina e responsabilidade para lidar com certas coisas desde cedo, com dinheiro, até com impostos".

Na mesma linha argumentativa, Grazi Massafera afirma se sentir triste quando as pessoas insistem em atribuir seu sucesso apenas à sorte: "Eu sempre batalhei muito, tive muita determinação em tudo que me propus a fazer". Mesmo não concordando que as mulheres têm a obrigação de se maquiarem, em entrevista para o Estadão, Grazi diz se sentir mais confiante maquiada:

Acredito que passar um batom vermelho, uma máscara de cílios pode transformar o dia... Aquele dia que a gente acorda se sentindo menos confiante, daí passa um batom incrível e até parece que mudou o jeito como você se enxerga e sai bem mais decidida para correr atrás dos nossos objetivos, sabe? [sic] $]^{10}$.

A referência à meritocracia é trabalhada nessa série como um valor que liga a imagem das marcas Eudora, Marina Ruy Barbosa e Grazi Massafera, estabelecendo, através de sentimentos e fatos cotidianos, uma relação afetiva de proximidade com a identidade da mulher brasileira. O valor meritocrático é o que caracteriza a legitimidade do sucesso de quem empreende, trocando a ilegitimidade da hereditariedade por esse modelo igualitário que tem como referência o próprio indivíduo enquanto figura de começo (EHRENBERG, 2010).

As afinidades com a audiência são buscadas a todo momento. É o caso do teaser protagonizado pelas porta-vozes, no qual Grazi Massafera inicia a fala com a seguinte pergunta: "Quem já teve vontade de jogar tudo pro alto e desistir, levanta a mão. [sic]". Visando reiterar o lugar em comum que elas ocupam na sociedade, afirma que esse é um sentimento mais comum do que se imagina: "Gente, todo mundo passa por isso".

É nessa mesma dimensão discursiva, altamente difundida na sociedade hoje, que também o trabalho de atores e cantores mirins é descaracterizado de trabalho infantil e reproduzido como fato lúdico associado aos sentidos de sonho e vocação. Embora

8 Disponível em: $<$ https://www.cosmeticinnovation.com.br/eudora-aposta-em-conceito-de-marca-coaching/> Acesso em 08 de nov. de 2018.

9 Disponível em: <https://blogs.oglobo.globo.com/marina-caruso/post/pago-impostos-desde-os-nove-anos-de-idade-diz-marina-ruy-barbosa.html > Acesso em 08 de nov. de 2018.

10 Disponível em: <https://emais.estadao.com.br/blogs/lindeza/fico-triste-quando-insistem-em-atribuir-minha-trajetoria-a-sorte-diz-grazi-massafera/> Acesso em 08 de nov. de 2018. 


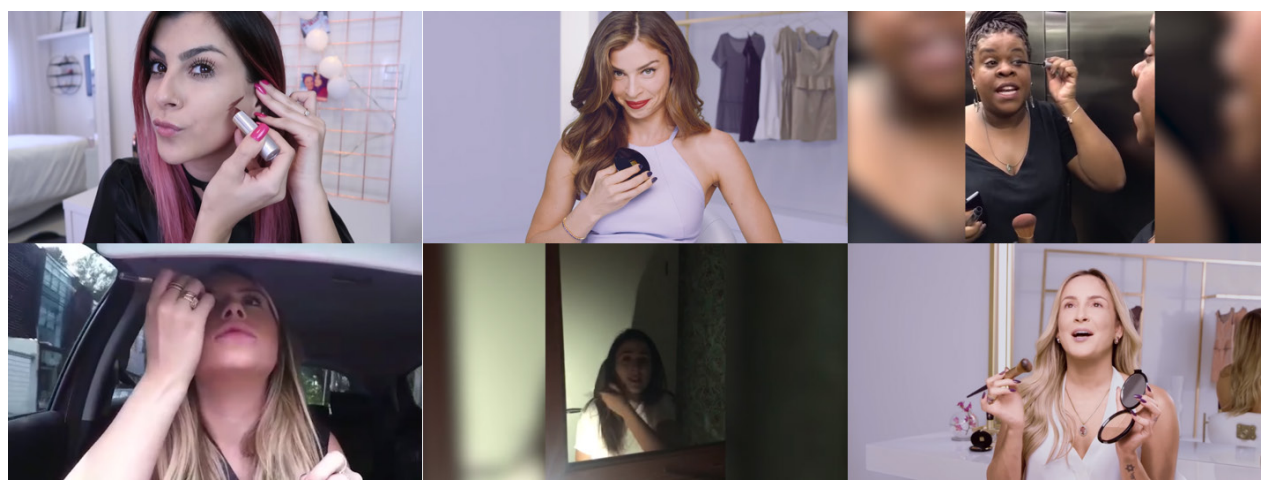

Figura 3 - Desafio Chega lá e Eudora com celebridades e influenciadoras digitais. Reprodução/YouTube.

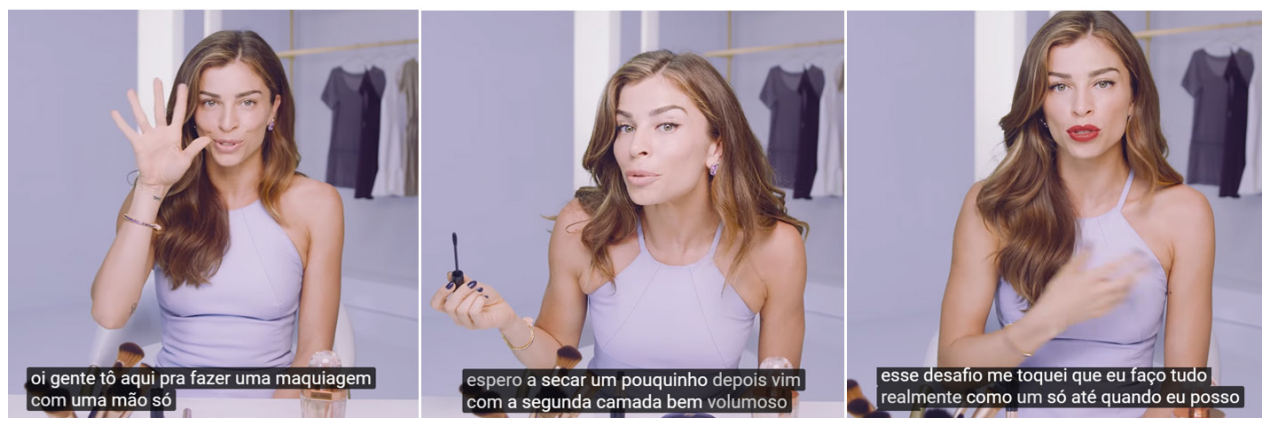

Figura 4 - Desafio Chega lá e Eudora | Grazi Massafera e a make só com uma mão. Reprodução/YouTube.

esse também seja um recurso manejado no discurso dessas celebridades e evocado nos vídeos a partir da memória discursiva da audiência, pouco se ligam à realidade de muitas consumidoras, especialmente porque não é qualquer pessoa que está autorizada a entrar nessa ordem do discurso, falar do trabalho infantil como "uma escolha" em virtude de "um sonho" ou de "uma vocação".

E se tratando do tema trabalho, a linguagem esportiva e do jogo é constantemente evocada para explicar e estimular atitudes, como é o caso da série "Desafio Chega lá e Eudora!", nos quais as protagonistas desafiam outras a realizarem alguma ação com os produtos Eudora. Ao todo, são 16 protagonistas (influenciadoras digitais e celebridades com contrato com a Rede Globo) que interagem entre si através de vídeos, aceitando e propondo desafios: Taís Araújo, Cacau Protásio, Ingrid Guimarães, Tatá Werneck, Bia e Branca, Gaby Amarantus, Juliana Paes, Juliana Alves, Cláudia Leitte, Nina Secrets, Evelyn Regly, Jade Seba, Nah Cardoso e as duas porta-vozes da marca, Marina Ruy Barbosa e Grazi Massafera.

Com desafios simples, a série se vale de metáforas esportivas, ancorada nos valores da ação, para estimular o espírito competitivo, pois vencer, no sentido proposto, é uma questão de atitude. De uma maquiagem feita apenas com batom ou uma mão, 
no elevador, no carro, no escuro ou sem espelho, o que se busca demonstrar é que conquistar é uma questão de "chegar lá e vencer". Segundo Ehrenberg (2010, p.25), a mitologia esportiva não se limita a evidenciar o indivíduo, mas forjá-lo, tornando-o "um indivíduo heroico que assume riscos, em vez de buscar proteger-se deles por meio das instituições do Estado-providência; que busca agir sobre si mesmo, em vez de ser comandado por outros".

Com bom humor e situações cômicas, as protagonistas dos frames acima desafiam umas às outras a se maquiarem de maneira inusitada, tendo como referência os desafios assumidos pelas mulheres no dia a dia. O discurso, todavia, é construído na controvérsia: por um lado, reforça a competição entre os sujeitos do sexo feminino, por outro, traz a cumplicidade como elemento de integração feminina.

Ao mesmo tempo, não se trata de um processo somente interativo, mas em diálogo com o sentido de marca-coaching, pois as protagonistas dos vídeos não só realizam os desafios, como também ensinam as consumidoras a fazerem o mesmo através da recorrência de sua memória afetiva. Como ressalta Grazi, "quem nunca teve que fazer uma maquiagem usando uma mão só?" (Figura 4) ${ }^{11}$.

A terceira série de teasers lançada pela campanha, "Eudora Responde", traz as porta-vozes Marina e Grazi, a cantora Cláudia Leitte e algumas influenciadoras digitais para interagirem com as consumidoras na plataforma da marca. Assumindo uma atitude de coaching, elas respondem a dúvidas enviadas pelas internautas e indicam produtos da Eudora como solução para os seus problemas, que vão desde um preparo simples de pele para maquiagem até uma forma de manter a pele sempre jovem.

Reapropriado por sujeitos leigos, o discurso especializado assume, na modernidade, uma função que transcende o mero aconselhamento. Busca, antes, ensinar através do exemplo. No caso da Eudora, as protagonistas funcionam, assim como as funcionárias da empresa nos pontos de venda, como coaches no assunto (assim como a própria marca, de modo geral, pretende ser), ascendendo o leigo à função de especialista. Isso ocorre "porque a informação especializada, como parte da reflexividade da modernidade, é de uma forma ou de outra constantemente apropriada pelos leigos" (GIDDENS, 2002, p.27).

Assumida como uma prática natural para as mulheres, essa tarefa de produzir a si mesma é reflexo de um longo processo de pedagogização da sexualidade cujas práticas de disciplinamento dos corpos reiteradamente o constituem. Tal pedagogia, segundo Louro (2016, p.17), "é muitas vezes sutil, discreta, contínua, mas, quase sempre, eficiente e duradoura", naturalizando, ao longo do tempo, as relações de dominação entre os sexos. A começar pela biologização da identidade. Para a autora, essas práticas continuamente constituem, através da produção de marcas, sujeitos femininos e masculinos. A publicidade, nesse sentido, como instância de (re)produção dessa pedagogia, reitera "identidades e práticas hegemônicas enquanto subordina, nega ou recusa outras identidades e práticas” (LOURO, 2016, p.25).

$\mathrm{Na}$ mesma perspectiva discursiva, a quarta série da campanha, "Mulheres que

11 Disponível em: <https://www.youtube.com/watch?v=tG8odHAaWoQ> Aceso em 08 de nov. de 2018. 


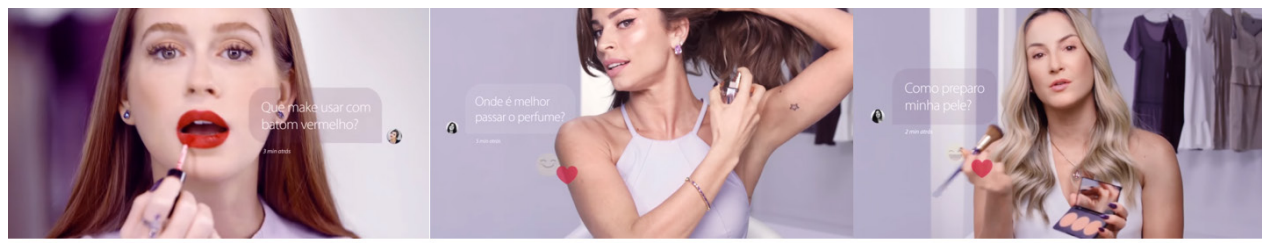

18 Maria Gabriella

Meninas como preparar a pele corretamente para receber a maquiagem?
(1) Tamires Schionato

Alguma dica de como cuidar da pele para deixá-la sempre jovem?

Figura 5 - Série Eudora Responde. Reprodução/YouTube.

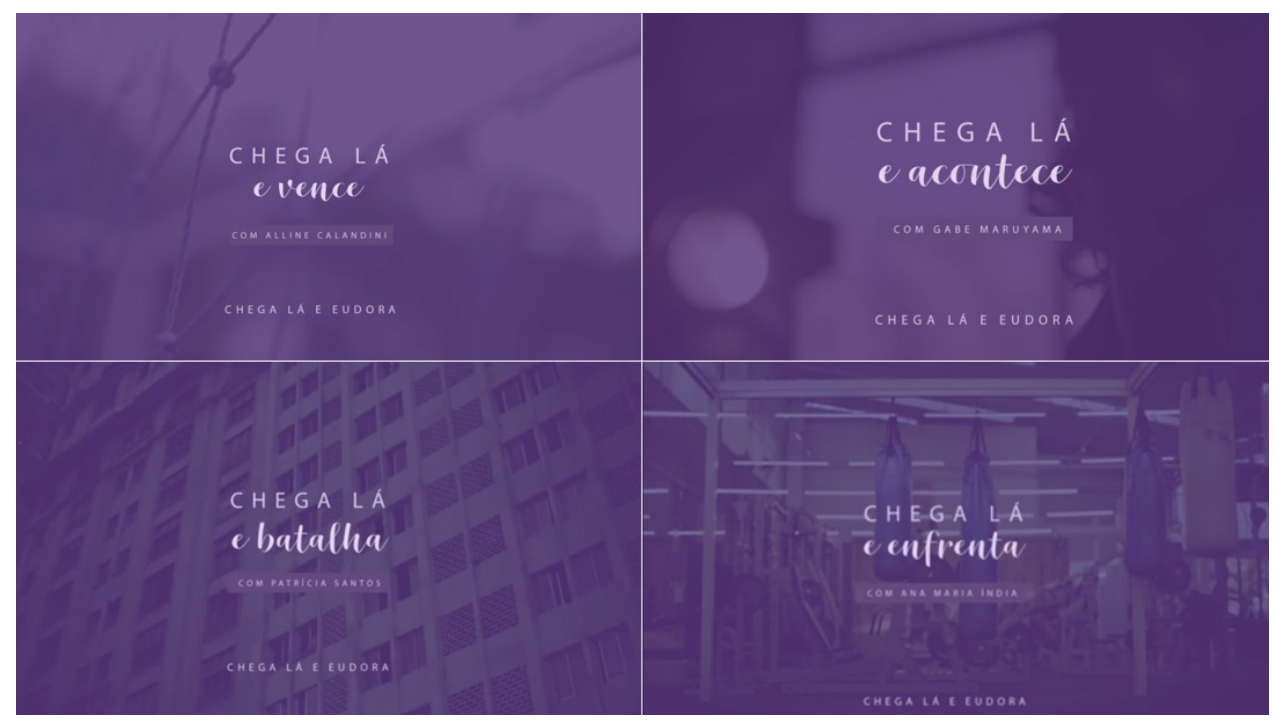

Figura 6 - Mulheres que inspiram a chegar lá. Reprodução/YouTube.

inspiram a chegar lá", tem como protagonistas três mulheres que relatam suas vidas segundo uma narrativa de superação. Os relatos que dão de si mesmas inspiram sobretudo porque representam modelos acessíveis de sucesso, narrando como foi possível "chegar lá." Evidenciam, em seu discurso, o protótipo do que Casaqui (2015) postula como cultura da inspiração, na qual o sucesso individual é erigido como modelo de conduta.

Os teasers "Chega lá e vence!”, “Chega lá e acontece!”, “Chega lá e batalha!” e "Chega lá e enfrenta!" materializam a noção de trajetória de vida como realidade construída evocada pela marca, que ao trazer o testemunho de mulheres com histórias de superação e sucesso, reforça a premissa de que "a ação empreendedora é eleita como o instrumento de um heroísmo generalizado" (EHRENBERG, 2010, p.13).

Ao que parece, a proposta da marca consiste em promover, através de exemplos e 
ensinamentos, um consumo consciente que estimula o empreendedorismo enquanto modelo de conduta, no qual o corpo feminino aparece como objeto a ser trabalhado e modificado permanentemente, a fim de proporcionar uma experiência agradável e produtiva para as mulheres que protagonizam sua própria história.

Os relatos apresentados na quarta série da campanha requerem um olhar mais atento no quesito competência afetiva: são histórias de pessoas "comuns" que constituem o sentido próprio de "virada" e por si constituem o discurso inspiracional tão evocado na publicidade contemporânea. Casaqui (2015) explica que, nesse contexto, a narrativação da própria vida em chave motivacional, com vistas a servir de modelo à trajetória do outro, ganha espaço crescente no aspecto da inspiração como cultura.

Para Allini Calandrini, jogadora profissional de futebol, seu chegar lá é encerrar a carreira " $100 \%$ realizada" ${ }^{12}$, enquanto que, para Patrícia Santos, consultora focada em diversidade étnico-racial, chegar lá tem a ver com abrir caminhos, "é ter o desafio de estar em grandes organizações para fazer esse processo de inclusão"13. Assim, a capacidade criativa do capitalismo parece se materializar na emergência do valor biográfico como qualidade de reinvenção de

si mesmo como objeto que pode inspirar. E é nisso que consiste a vantagem suplementar da autobiografia: para além da captura do leitor em sua rede peculiar de veracidade, ela permite ao enunciador a confrontação rememorativa entre o que era e o que chegou a ser, isto é, a construção imaginária de "si mesmo como outro" (ARFUCH, 2010, p.55).

Para tanto, as narrativas de autoajuda que esses relatos visam se ancorar se apresentam como uma atualização dos testemunhos religiosos, que, através da promoção de técnicas de exercícios de si no formato de exemplo, remetem a uma espiritualidade porque promovem o aperfeiçoamento de modos de existência. Nesse embricamento, portanto, entre ferramentas seculares e religiosas de cuidados de si, o sofrimento afetivo, combinado à aspiração e à autorrealização tornam-se os meios pelos quais a identidade moderna torna-se "cada vez mais publicamente encenada numa variedade de locais sociais" (ILLOUZ, 2011, p.12).

Ao propor uma campanha inovadora, a Eudora promove um tipo particular de empoderamento que condiciona a confiança à estética da aparência. Nesse sentido, reforça um "poder feminino" que associa o bem-estar à aparência física. A campanha se apropria de padrões para proferir um discurso inspiracional na qual sentimentos como autoestima e autoconfiança são ainda mais possíveis quando essas mulheres estão maquiadas.

Com isso, ao lançar a campanha "Chega lá e Eudora”, a marca empreende um tipo de publicidade transestética, inspirado no discurso meritocrático de autoajuda que é

12 Disponível em: <https://www.youtube.com/watch?v=LmAqlK_E2-E> Acesso em 08 de nov. de 2018.

13 Disponível em: <https://www.youtube.com/watch?v=D6ThCFd_CX0> Acesso em 08 de nov. de 2018. 


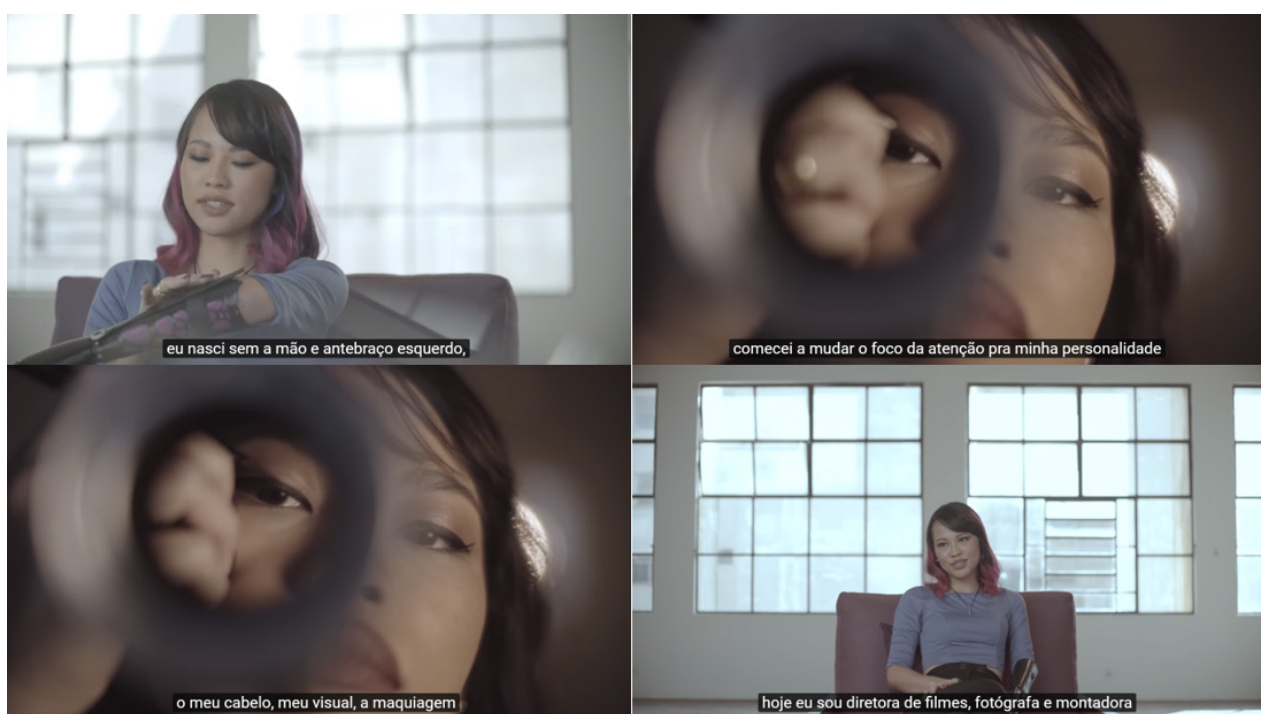

Figura 7 - Mulheres que inspiram a chegar lá: Gabe Maruyama | Eudora. Reprodução/YouTube.

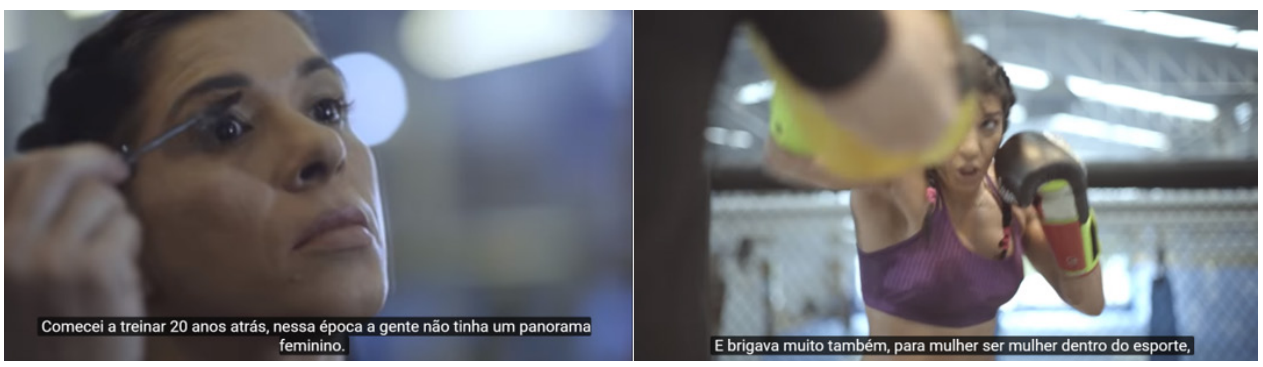

Figura 8 - Mulheres que inspiram a chegar lá: Ana Maria Índia | Eudora. Reprodução/YouTube.

atravessado por essa cultura que enseja cada vez em nossas mentes o desejo para inspirar. Nessa era da felicidade compulsiva e compulsória que a marca-coaching se insere, "convém aparentar-se bem adaptado ao ambiente, irradiando confiança e entusiasmo, alardeando uma personalidade desembaraçada, extrovertida e dinâmica" (FREIRE FILHO, 2010, p.17).

Seus exemplos são os mais variados: desde a menina (Figura 7) que sofreu preconceitos por conta de uma deficiência congênita e encontrou na personalidade - materializada sobretudo na aparência - um modo de deslocar a atenção para o seu eu interior, até a atleta que brigou muito "para a mulher ser mulher dentro do esporte e estar dentro do tatame linda, pois isso não ia mudar a minha luta"14 (Figura 8).

14 Disponível em: <https://www.youtube.com/watch?v=ROz63Ato538> Acesso em 08 de nov. de 2018. 
Essa nova cena publicitária na qual Eudora se insere é, de acordo com Lipovetsy e Serroy (2015, p.223), inseparável da cultura individualista contemporânea, "que trabalhou para privilegiar a originalidade, o divertimento, o humor, mas também as atmosferas emocionais que dão aos espectadores a sensação de não serem comandados de fora”. Assim, como foi apresentado, mesmo que as celebridades sejam ainda um recurso bastante utilizado por essa publicidade em transformação, a inspiração enquanto cultura (CASAQUI, 2017) tem produzido um efeito direto na produção de seu discurso.

\section{Considerações finais}

A busca de estratégias de mercado para expressar a tonalidade particular da subjetividade contemporânea representa, segundo Arfuch (2010), o valor autobiográfico assumido pelo capitalismo tardio, de alta capacidade inventiva, e, como ele, o novo espírito publicitário, que "preconiza a ideia criativa contra a repetição mecanicista do reclame, a participação afetiva do consumidor" (LIPOVETSKY; SERROY, 2015, p.222).

No caso da campanha “Chega lá e Eudora!", ao invés de um discurso pautado na instrumentalidade de "produtos que dão resultados", o que vemos é o que os autores chamam de "convites à viagem e ao sentir". Desse modo, com a proposta de que "a beleza traz confiança e inspiração para cada mulher fazer a vida acontecer", a Eudora lança mão de um projeto de publicidade inovadora que busca, através de exemplos de mulheres bem-sucedidas, inspirar sua audiência através do estímulo ao consumo de seus produtos. É nesse contexto que surge o conceito de marca-coaching, buscando "ensinar" às consumidoras como obterem autoestima e autoconfiança em suas vidas.

$\mathrm{O}$ discurso inspiracional emerge nessa campanha em um sentido controverso, mas alinhado aos postulados do novo espírito do capitalismo: ainda que de formas contraditórias, ele incita a ação através de novas formas de ação nas esferas do trabalho e do consumo. Assim, ao mesmo tempo em que busca estimular a transformação da sociedade em um lugar mais justo e igualitário, o faz por meio da promoção de valores meritocráticos, o que é essencialmente contraditório quando se trata de uma sociedade historicamente marcada pela desigualdade social.

Contudo, percebemos que o processo criativo desse fazer publicitário ainda se respalda em padrões identitários para legitimar suas ações, como na campanha em questão. No alicerce desse discurso de empoderamento ainda percebemos as estruturas de um modelo de cultura patriarcal que posiciona esse outro, a mulher, em um lugar em que alcançar o sucesso profissional, por exemplo, é um feito sempre difícil e cuja aparência é uma condição que ainda valida seu poder de transformação.

Ao incorporar o ethos ativista como modo de conduzir uma campanha "que inspira as mulheres a chegarem lá", a marca tem o mérito de produzir um tipo de publicidade diferenciada, dando visibilidade a alguns sujeitos tradicionalmente ofuscados na publicidade. Todavia, seu discurso ainda reforça certos estereótipos ligados às noções de sucesso e felicidade para as mulheres. Então nos encontramos em um 
grande dilema que consiste em pensar os limites e as possibilidades da publicidade contemporânea como ferramenta de visibilidade das causas sociais.

\section{Referências}

ARFUCH, Leonor. O espaço biográfico: dilemas da subjetividade contemporânea. Rio de Janeiro: EdUERJ, 2010.

BOLTANSKI, L.; CHIAPELLO, È. O novo espírito do capitalismo. São Paulo: Martins Fontes, 2009.

CASAQUI, Vander. Abordagem crítica da cultura da inspiração: produção de narrativas e o ideário da sociedade empreendedora. E-Compós, Brasília, v.20, n.2, p.01-18, 2017.

DOMINGUES, Izabela; MIRANDA, Ana Paula. Consumo de ativismo. São Paulo: Estação das Letras e Cores, 2018.

EGGS, Ekkehard. Ethos aristotélico, conviç̧ão e pragmática moderna. In: AMOSSY, Ruth (org). Imagens de si no discurso: a construção do ethos. $2^{\mathrm{a}}$ Ed. São Paulo: Contexto, p.29-56, 2013.

EHRENBERG, Alain. O culto da performance: da aventura empreendedora à depressão nervosa. São Paulo: Ideias \& Letras, 2010.

FREIRE FILHO, João. O anseio e a obrigação de ser feliz hoje. In: FREIRE FILHO, João (org). Ser feliz hoje: reflexões sobre o imperativo da felicidade. Rio de Janeiro: Editora FGV, 2010. FOUCAULT, Michael. História da sexualidade 2: o uso dos prazeres. Rio de Janeiro: Edições Graal, 1985.

GIDDENS, Anthony. Modernidade e identidade. Rio de Janeiro: Jorge Zahar Editor, 2002.

ILLOUZ, Eva. O amor nos tempos do capitalismo. Rio de Janeiro: Zahar, 2011.

LIPOVETSKY, Gilles; SERROY, Jean. A estetização do mundo: viver a era do capitalismo artista. São Paulo: Companhia das Letras, 2015.

MARÍN-DIAZ, Dora L. Autoajuda, educação e práticas de si: genealogia de uma antropotécnica. Belo Horizonte: Autêntica, 2015.

MAINGUENEAU, Dominique. Cenas da enunciação. São Paulo: Parábola Editorial, 2008. 


\title{
"Get there and Eudora!": Activism and inspirational discourse of the brand-coaching advertising campaign
}

\begin{abstract}
This paper investigates, since the case study of the advertising campaign "Get there and Eudora!", how the inspirational discourse typical of the self-help market has promoted changes in contemporary advertising, especially in the cosmetics market, known for reinforcing stereotypes and beauty standards. Therefore, we use the notion of ethos (Maingueneau, 2008, Eggs, 2013) to analyze how the Eudora brand builds its image based on forms of social activism. The 'expanded' corpus includes advertising pieces in various formats, and the 'restricted' corpus contain the videos published by the Eudora channel on Youtube, whose target audience are consumers and women seeking to increase their income by selling cosmetics. The study demonstrates how self-help narratives constitute the ideal format for promoting a self-image of brands, such as Eudora, in accordance with the different forms of engagement and social activism.
\end{abstract}

\section{Keywords}

Advertising. Culture of inspiration. Social activism. Activist ethos. Self-help discourse.

\section{Sobre as autoras}

Emanuelle Gonçalves Brandão Rodrigues. Doutoranda em Comunicação pela Universidade Federal de Pernambuco (UFPE).

egbrodrigues@gmail.com

Danyelle Alves da Paixão. Estudante de Graduação do $8^{\circ}$ semestre do Curso de Relações Públicas da Universidade Federal de Alagoas (UFAL).

danyellealves_p@hotmail.com

Thainá Evellyn Martiniano Alexandre. Estudante de Graduação do $8^{\circ}$ semestre do Curso de Relações Públicas da Universidade Federal de Alagoas (UFAL).

thaynamartiliano@gmail.com 